\title{
Sistem Monitoring dan Kontrol Motor AC 1 Phasa Dengan Fuzzy Logic Controller Berbasis Arduino Uno
}

\author{
Aifiayu $^{1}$, Ta' $^{\prime}{ }^{2}{ }^{2}$ \\ ${ }^{1}$ Universitas Negeri Padang \\ Jl. Prof Dr. Hamka Air Tawar, Padang, Indonesia \\ aiaifiayu@gmail.com ${ }^{1}$
}

\begin{abstract}
The AC Motor is the most used in the current industry, because the AC Motor has flexible properties. Also, when the AC Motor is given weight, the torque on the ac bike increases, which can cause the speed of the air to decrease. Therefore the research was to control and monitor which could improve the speed of the 1 phase AC Motor weight with method Fuzzy Logic Controller. It's designed using softwere and hardwere. The hard component of hardwere used is the intensity of Power Supply, Arduino Uno, speed sensors, Gate Drives, 1 Phase AC Motor and softwere among those, softwere Arduino IDE, and also visual basic to control the speed of 1 phase AC motor. This research has been successful in stabilizing the speed of 1 phase AC Motor. 295 watts and 395 watts use fuzzy logic method the controller based Arduino Uno and can pinpoint the transient on the response Fuzzy Logic Controller.
\end{abstract}

Keywords - AC Motor, Arduino Uno, Gate Drive, Fuzzy Logic Controller.

Abstrak- Motor AC merupakan motor yang paling banyak digunakan pada industry saat sekarang ini, dikarenakan Motor AC mempunyai sifat yang fleksibel. Selain itu terdapat kekurangan pada Motor AC salah satunya yaitu pada saat Motor AC diberikan beban maka torsi pada Motor AC menjadi besar, hal tersebut dapat mengakibatkan kecepatan Motor AC menurun. Maka dari itu penelitian ini bertujuan untuk mengontrolan dan monitoring yang dapat mesntabilkan kecepatan saat Motor AC 1 Phasa berbeban dengan method Fuzzy Logic Controller. Pada perancangan alat ini menggunakan softwere dan hardwere. Komponen hardwere yang digunakan ialah rangakaian power supply, Arduino Uno, sensor kecepatan, Gate Drive, Motor AC 1 Phasa dan softwere diantaranya softwere Arduino IDE yang berisi pemrograman bahasa C dalam mengatur kecepatan Motor AC 1 Phasa dan juga softwere Visual Basic untuk memeonitoring kecepatan Motor AC. penelitian ini telah berhasil dalam menstabilkan kecepatan putaran motor AC 1 Phasa dengan kecepataan yang diinginkan saat ditambahkan beban lampu 60 watt, 120 watt, 195 watt, 295 watt dan 395 watt menggunakan metoda Fuzzy Logic Controller berbasis Arduino Uno dan dapat menentukan Transient pada response Fuzzy Logic Controller.

Kata kunci-Motor AC, Arduino Uno, Gate Drive, Fuzzy Logic Controller.

\section{Pendahuluan}

Motor berfungsi merubah energi listrik meenjadi energi mekanik. Penggunaan motor listrik banyak terdapat pada peralatan mesin di perindustrian serta peralatan rumah tangga. Motor Ac merupakan motor yang paling banyak ditemui pada peralatan idustri maupun peralatan rumah tangga[1]. Kontruksi yang sederhana, relatif murah, lebih ringan dan memiliki efesiensi yang tinggi serta murdah dalam pemeliharaanya menjadikan motor Induksi banyak digunakan sebagai penggerak utama peralatan perindustrian[2]. Namun dalam hal pengaturan kecepatan, motor induksi susah untuk di kontrol karena motor induksi memiliki beberapa parameter yang bersifat non-linear dan juga pada resistansi rotor yang memiliki variasi nilai untuk operasi yang berbeda[3].

Kecepatan Motor Induksi tidak dapat Stabil apabila terjadi perubahan beban. Dengan memberikan beban pada motor induksi dapat merubah kecepatan putaran motor induksi[4]. Semakin besar beban yang diterima motor, maka torsi pada motor induksi akan semakin besar pula, hal tersebut dapat menghambat laju motor induksi[5]. Ada beberapa cara yang bisa dilakukan untuk mengendalikan kecepatan putaran motor induksi yaitu dengan mengubah jumlah kutub dan mengubah tegangan stator[6].

Oleh karena itu, dibutuhkannya sebuah alat yang dapat mengontrol dan memonitoring kecepatan putaran motor sehingga dapat mempermudah pekerjaan manusia. Alat ini nantinya menggunakan perangkat keras mikrokontroler sebagai otak pengolah data yang dimasukkan kedalamnya[7]. Kontrol yang akan digunakan yaitu Fuzzy Logic Controller . Fuzzy Logic Controller ini memiliki kelebihan yang mana proses kendalinya relatif mudah, fleksibel sehingga tidak melibatkan model matematis yang rumit dari sistem yang akan dikendalikan[8]. Tahapan Fuzzy Logic Controller terbagi atas tiga bagian diantaranya fuzzyfikasi, evaluasi rule dan defuzzyfikasi[9]. Nantinya data kecepatan yang didapatkan dari methoda Fuzzy Logic akan dikirimkan ke PC (Perconal Computer), ini bertujuan 
untuk mudah mengetahui terjadinya perubahan kecepatan sehingga dapat mempermudah dalam mnganalisis kerusakan yang terjadi pada motor, hal ini lebih dikenal sebagai interface[10].

Penelitian ini akan membuat sebuah sistem yang dapat menstabilkan kecepatan motor induksi berbeban dengan menggunakan kontrol fuzzy logic berbasis Arduino Uno, dan akan dimonitoring datanya oleh komputer.

\section{Metode}

Pada Penelitian ini merancang sebuah sistem yang dapat memonitoring dan mongontrol kecepatan putaran motor berbeban agar kecepatan motor tetap sesuai dengan setting poin yang diinginkan menggunakan Fuzzy Logic Controller berbasis Arduino Uno. Dan melalukan pengujian pada setiap komponen.

\section{A. Blok Diagram}

perancangan dari sistem monitoring dan kontrol motor ac 1 phase menggunakan Fuzzy Logic Controller berbasis Arduino Uno. Adapun blok diagram dari alat seperti dibawah ini.

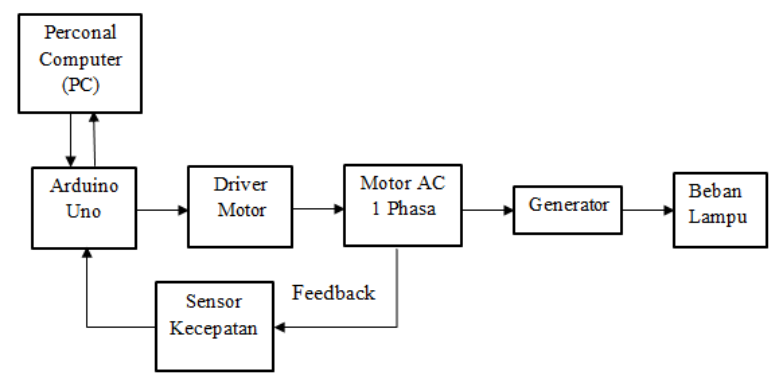

Gambar 1. Blok Diagram

Berdasarkan dari blok diagram diatas , fungsi dari masing-masing blok diagram sebagai beriku:

1. Arduino Uno merupakan bagian yang berfungsi untuk memproses input yang dimasukan dan menghasilkan output berupa aktifasi pada kendali motor AC dengan method Fuzzy Logic menggunakan Aduino Uno

2. Sensor Kecepatan merupakan sensor yang difungsikan untuk mendeteksi kecepatan dari motor AC dalam satuan RPM (Rotation Per Minute)

3. PC (Perconal Computer) berfungsi untuk mengetahui dan memonitoring kecepatan motor AC saat aktif

4. Driver Motor digunakan untuk mengatur kecepatan motor induksi ketika berbeban.

5. Motor AC berfungsi sebagai objek yang akan diuji dalam membaca kecepatan motor dan menerapkan method Fuzzy Logic Controller.

6. Generator berfungsi sebagai beban dari motor AC yang nantinya akan di couple dengan motor AC. Hasil dari putaran motor akan menggerakkan generator, dari penggerakan tersebut akan menghasilkan daya listrik.

7. Lampu AC berfungsi sebagai beban keluaran dari generator, yang dapat mempengaruhi kecepatan motor AC.

\section{B. Flowchart}

Flowchart merupakan urutan intruksi program dalam suatu diagram. Pada flowchart menjelaskan urutan sistem pengontrolan motor AC

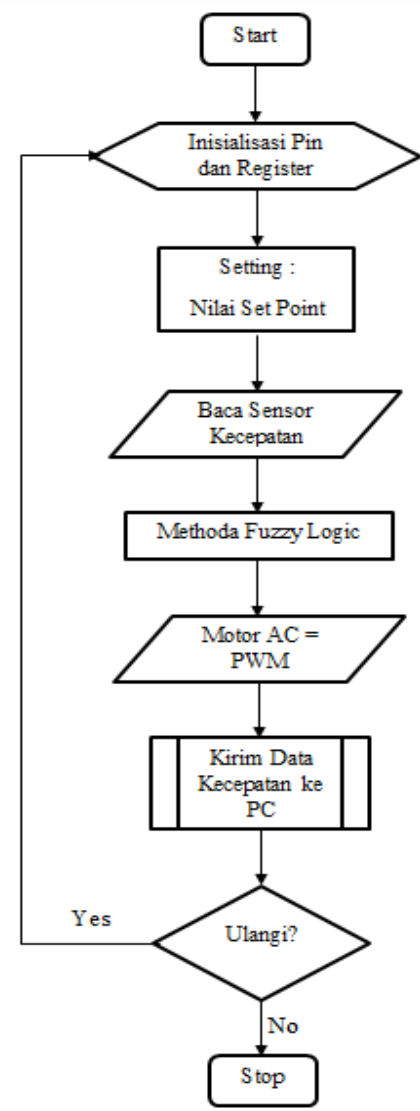

Gambar 2. Diagram Alur Sistem Arduino

Pada gambar 2. Menjelasakan alur yang terdapat pada sistem Arduino Uno diantaranya yaitu insialisasi Pin dan Register oleh Arduino Uno, kemudian mensetting kecepatan sesuai yang diinginkan, sensor akan membaca kecepatan putaran motor AC, kemudian control logika Fuzzy untuk mengurangi kesalahan pada putaran motor agar motor dapat berputar sesuai dengan keingiinan. Cepat lambatnya kecepatan motor bergantung pada PWM (pulsa With Modulation), semakin cepat putaran motor maka nilai PWM semakin besar, begitu sebaliknya. Data Kecepatan yang diterima oleh Arduino Uno akan diolah dan dikirmkan ke PC (Perconal Computer).

\section{Perancangan Hardware}

Perancangan Hardware harus sesuai dengan spesifikasi dan cara kerja dari sistem yang hendak dibuat. Bentuk perancangan hardware yang dibuat berupa box yang berisi 
rangkaian untuk mengontrol Kecepatan motor AC 1 phasa diantaranya yaitu Power Supply, Driver motor. Zero Crossing, Arduino Uno dan Sensor Pembagi Tegangan.

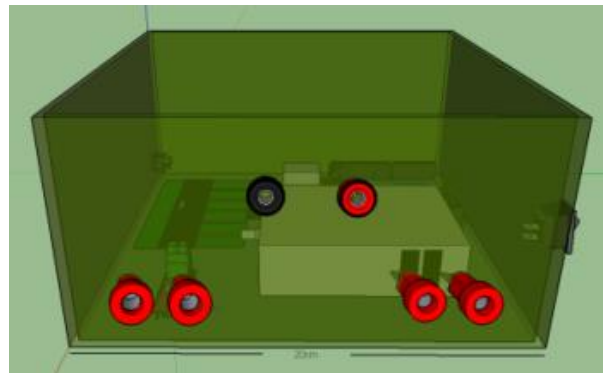

Gambar 3. Bentuk Alat

\section{Perancangan Rangakaian Elektronika Secara} Keseluruhan

Pada perancangan rangakaian elekktronika keseluruhan ini terdapat, rangakain komponenkomponen yang diperlukan untuk rancangan pengontrolan kecepatan motor AC 1 phasa. Diantaranya rangakain Power Supply menggunakan IC LM7805, Rangkaian pembagi tegangan menggunakan 2 buah resistor, rangakain Driver Motor menggunakan rangkaian MOC 3021 dan triac BT 136, dan rangkaian Zero Crossing menggunskan IC LM358.

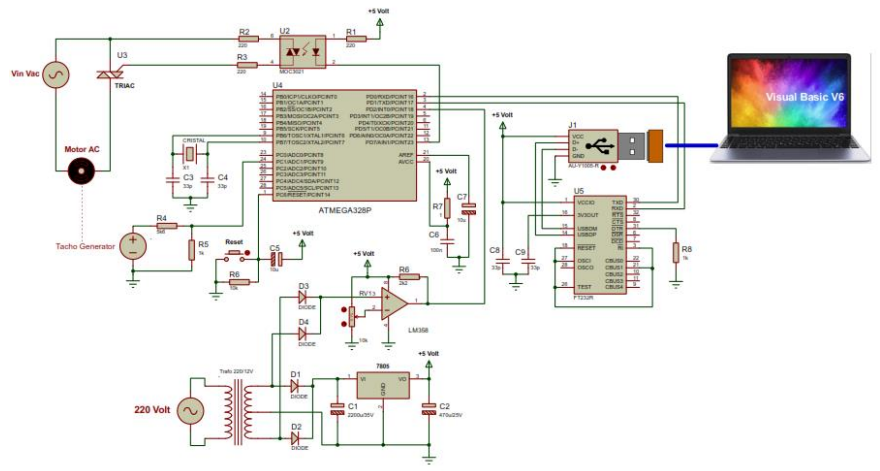

Gambar 4. Rangakain Elektronika Keseluruhan

\section{HASIL DAN PEMBAHASAN}

Suatu peralatan atau program diakatakan bekerja dengan baik apabila telah disertai dengan pembuktian terhadap fungsi kerja dari perlatan tersebut. Pengujian dilakukan terhadap pengakat keras (Hardware) dan perangkat lunak (Software). Berikut merupakan gambar pengujian pengontrolan Motor AC 1 Phasa menggunakan beban lampu 60 watt, 120 watt, 195 watt, 295 watt, dan 395 watt.

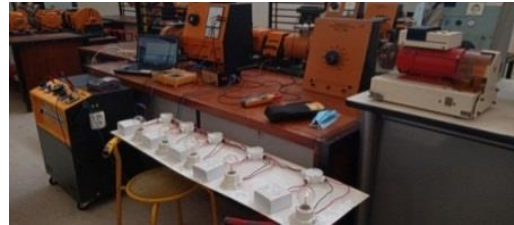

Gambar 5. Bentuk Rangkaian Keseluruhan

\section{A. Pengujian Power Supply}

Pengujian ini bertujuan untuk mengetahui rangakaian power supply dapat bekerja dengan baik sehingga dapat menyuplay mikrokontroler Arduino dan Rangkaian Gate Drive. Pengujian Power Supply dilakukan pada transformator, terminal output dan tegangan regulator.

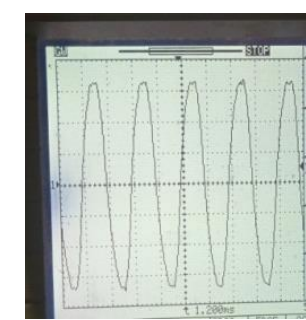

\section{Gambar 6. Pengujian Gelombang Power Supply} 12Vac

Dari Pengukuran didapatkan besar tegangan keluaran dari transformator adalah $12 \mathrm{~V}$.

\section{B. Pengujian Gate Drive}

Pengujian dilakukan dengan cara menghubungkan rangakain Gate Drive dengan power supply $5 \mathrm{Vdc}$, dan menghubungkan sinyal keluaran PWM yang dihasilkan oleh mikrokontroler Arduino Uno.

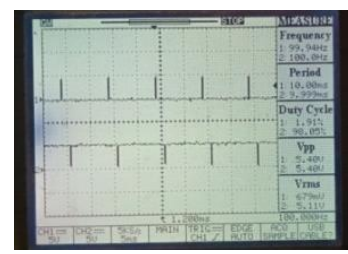

Gambar 7. Gelombang Output Gate Drive duty cycle sebesar $98 \%$

Dari pengujian didapatlkan nilai Duty Cycle sebesar 98.05\%, Vrms sebesar 5.11 V dan frequensi sebesar 99,99 $\mathrm{Hz}$.

\section{Hasil Pengujian dan Analisa Perangkat}

Dilakuakan pengujian kecepatan motor AC 1 Phasa berbeban dengan variasi beban yaitu 60 watt, 120 watt, 195 watt, 295 watt, dan 395 watt dengan setting poin 500 RPM. 


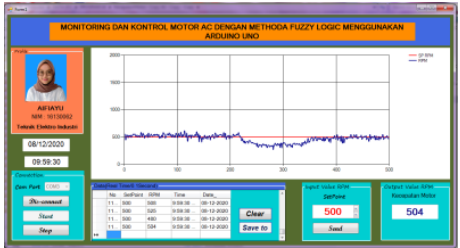

Gambar 8. Grafik pembacaan Sensor dengan beban 60 Watt

Hasil pengujian saat kecepatan putaran motor diberikan setting poin 500 RPM dengan beban 60 Watt, dengan menggunakan method Fuzzy Logic Controller dibutuhkan waktu sekitar 16 detik untuk menstabilkan kecepatan sesuai setting poin yang diberikan.

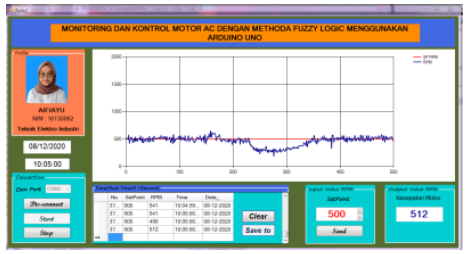

Gambar 9. Grafik Pembacaan Sensor dengan Beban 120 Watt

Hasil pengujian saat kecepatan putaran motor diberikan setting poin 500 RPM dengan beban 120 Watt dengan menggunakan method Fuzzy Logic Controller dibutuhkan waktu sekitar 18 detik untuk menstabilkan kecepatan sesuai setting poin yang diberikan.

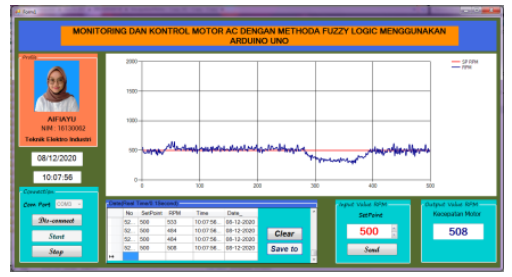

Gambar 10. Grafik Pembacaan Sensor dengan Beban 195 Watt

Hasil pengujian saat kecepatan putaran motor diberikan setting poin 500 RPM dengan beban 195 Watt dengan menggunakan method Fuzzy Logic Controller dibutuhkan waktu sekitar 19 detik untuk menstabilkan kecepatan sesuai setting poin yang diberikan.

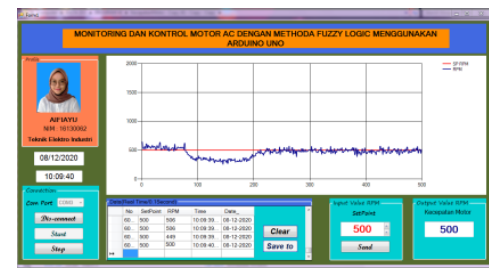

Gambar 11. Grafik Pembacaan Sensor dengan Beban 295 Watt

Hasil pengujian saat kecepatan putaran motor diberikan setting poin 500 RPM dengan beban 295 Watt dengan menggunakan method Fuzzy Logic Controller dibutuhkan waktu sekitar 20 detik untuk menstabilkan kecepatan sesuai setting poin yang diberikan.

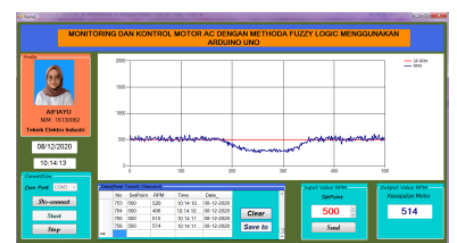

\section{Gambar 11. Grafik Pembacaan Sensor dengan Beban 395 Watt}

Hasil pengujian saat kecepatan putaran motor diberikan setting poin 500 RPM dengan beban 395 Watt dengan menggunakan method Fuzzy Logic Controller dibutuhkan waktu sekitar 20 detik untuk menstabilkan kecepatan sesuai setting poin yang diberikan. Berikut dijabarkan hasil pengujian keseluruhan.

TABEl I. PENGujIAN Berbeban

\begin{tabular}{|c|c|c|c|c|c|}
\hline No & $\begin{array}{c}\text { Beban } \\
\text { Lampu }\end{array}$ & $\begin{array}{c}\text { Set } \\
\text { Poin }\end{array}$ & Vinput & Imotor & $\begin{array}{c}\text { RPM } \\
\text { Data }\end{array}$ \\
\hline 1 & $\begin{array}{c}60 \\
\text { Watt }\end{array}$ & 500 & $145 \mathrm{~V}$ & $2.8 \mathrm{~A}$ & 504 \\
\hline 2 & $\begin{array}{c}120 \\
\text { Watt }\end{array}$ & 500 & $145 \mathrm{~V}$ & $3.3 \mathrm{~A}$ & 512 \\
\hline 3 & $\begin{array}{c}195 \\
\text { Watt }\end{array}$ & 500 & $145 \mathrm{~V}$ & $3.9 \mathrm{~A}$ & 508 \\
\hline 4 & $\begin{array}{c}295 \\
\text { Watt }\end{array}$ & 500 & $145 \mathrm{~V}$ & $4.5 \mathrm{~A}$ & 500 \\
\hline 5 & $\begin{array}{c}295 \\
\text { Watt }\end{array}$ & 500 & $145 \mathrm{~V}$ & $5.2 \mathrm{~A}$ & 514 \\
\hline
\end{tabular}

\begin{tabular}{|c|c|c|c|c|}
\hline No & $\begin{array}{c}\text { RPM } \\
\text { Terukur }\end{array}$ & $\begin{array}{c}\mathbf{V} \\
\text { generator }\end{array}$ & $\begin{array}{c}\text { I } \\
\text { Generator }\end{array}$ & $\begin{array}{c}\text { Waktu } \\
(\mathbf{s})\end{array}$ \\
\hline 1 & 520 & $82 \mathrm{~V}$ & $0.1 \mathrm{~A}$ & 16 \\
\hline 2 & 520 & $75.2 \mathrm{~V}$ & $0.2 \mathrm{~A}$ & 18 \\
\hline 3 & 520 & $70 \mathrm{~V}$ & $1.5 \mathrm{~A}$ & 19 \\
\hline 4 & 520 & $65.7 \mathrm{~V}$ & $2 \mathrm{~A}$ & 20 \\
\hline 5 & 520 & $60.7 \mathrm{~V}$ & $2.3 \mathrm{~A}$ & 20 \\
\hline
\end{tabular}

Pada Tabel 1. Merupakan hasil pengujian dari pengontrolan kecepatan motor menggunakan sensor kecepatan. Pada sensor kecepatan ini terdapat ketidak akuratan pembacaan dikarenakan tidak sempurnanya kalibrasi sensor tersebut. Adapun rumus dari nilai persentase error dan rata-rata error dari pengukuran kecepatan menggunakan sensor kecepatan yaitu :

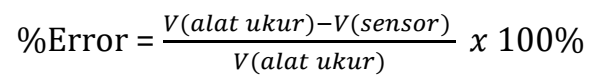

Tabel 2. Perhitungan Error Sensor

\begin{tabular}{|c|c|c|c|}
\hline $\begin{array}{c}\text { RPM } \\
\text { Data }\end{array}$ & $\begin{array}{c}\text { RPM } \\
\text { Terukur }\end{array}$ & Selisih & Error \% \\
\hline 504 & 520 & 16 & $3.1 \%$ \\
\hline 512 & 520 & 8 & $1.5 \%$ \\
\hline 508 & 520 & 12 & $2.3 \%$ \\
\hline 500 & 520 & 20 & $3.8 \%$ \\
\hline 514 & 520 & 6 & $1.2 \%$ \\
\hline \multicolumn{3}{|c|}{ Rata-rata error $(\%)$} & $2.38 \%$ \\
\hline
\end{tabular}


Berdasarkan pengujian didapatkan rata-rata error yang dihasilkan dari kalibrasi sensor kecepatan adalah $2.38 \%$. Pengujian Transient pada Response Fuzzy Logic memiliki kecepatan respon yang diukur saat $\mathrm{t}=0$ sampai dengan $63,2 \%$ dari respon respon stady state. Rise time atau waktu penaikan yang dibutuhkan oleh method Fuzzy Logic dalam penelitian ini berkisar antara 4 detik pada pergerakan atau kecepatan putaran motor mencapai respon steady state. Settling time rata-rata dari Fuzzy Logic Controller berkisar 9 detik yang merupakan waktu $5 \%$ hingga sampai pada kondisi steady state. Maximum overshoot yang dialamai pada pengujian ini adalah $3.6 \%$ dari respon stady state. Lonjakan atau maximum overshoot yang terjadi pada pengujian ini masih dalam batas normal. Dari hasil overshoot ini dapat diketahui menggunakan method Fuzzy Logic Controller dengan memanfaatkan rule dapat menghandle overshoot yang terjadi pada sistem.

\section{Penutup}

Pengontrolan Kecepatan Motor AC menggunakan metoda Fuzzy Logic Controller ini membutuhkan waktu untuk mencapai nilai constant atau nilai set poin yang diinginkan. Dan dengan pemanfaatan rule pada metoda fuzzy logic dapat menghandle terjadinya overshoot pada sistem dengan baik.

\section{REFERENSI}

[1] A. Sani, E. Eka, and N. Jannah, "Purwarupa Pengendali Kecepatan Motor Induksi 1 Fasa Via Android," vol. 12, no. 2, pp. 88-91, 2020.

[2] N. Evalina and A. A. Zulfikar, "Pengaturan Kecepatan Putaran Motor Induksi 3 Fasa Menggunakan Programmable Logic Controller," J. Electr. Technol., vol. 3, no. 2, pp. 73-80, 2018.

[3] R. I. Putri, M. Fauziyah, and A. Setiawan, "Penerapan Kontroler Neural Fuzzy Untuk Pengendalian Kecepatan Motor Induksi 3 Fasa Pada Mesin Sentrifugal," INKOM J. Informatics, Control Syst. Comput., vol. 3, no. 1, pp. 53-65, 2009.

[4] R. I. Putri, "Penerapan Adaptif Fuzzy Pada Pengaturan Kecepatan Motor Induksi Tiga Fasa," J. Tek. Gelagar, vol. 18, no. 1, pp. 57-64, 2007.

[5] D. M. Harfina, "Sistem Pengendali Motor Induksi pada Belt Conveyor dengan Teknik Vektor Kontrol pada VFD menggunakan MATLAB / Simulink," vol. 6, no. 1, pp. 1324, 2019.

[6] A. R. Putra, M. A. Novianta, S. Priyambodo, and T. A. Yogyakarta, "Pengendalian Kecepatan Motor Induksi Ac 1 Phasa Berbasis Mikrokontroler Atmega8535 Dengan
Penampil LCD016L Atmega8535 Dengan Penampil Lcd016l," vol. 2, no. 2, pp. 19-26.

[7] R. Hidayat, D. Notosudjono, and D. Suhendi, "Pengaturan Kecepatan Putaran Motor Induksi 1 Phasa Berbasis Mikrokontroler Atmega8535," Progr. Stud. Tek. Elektro Fak. Tek. Univ. Pakuan Bogor, pp. 1-10, 2013.

[8] J. T. Elektro and F. Teknik, "Aplikasi Fuzzy Logic untuk Pengendali Motor DC Berbasis Mikrokontroler ATMega8535 dengan Sensor Photodioda," J. Tek. Elektro, vol. 7, no. 2, pp. 81-85, 2015, doi: $10.15294 /$ jte.v7i2.8594.

[9] S. Sasongko and A. Hermawan, "Implementasi Fuzzy Logic Controller sebagai Pengendali Posisi Motor Servo," 2018.

[10] D. Apdilah, "Akuisisi Data Motor 1 Phasa 60 Watt Sebagai Pendeteksi Kecepatan Putaran," pp. 1-5, 2019.

\section{Biodata Penulis}

Aifiayu, lahir di Solok, 04 September 1998. Menyelesaikan Studi DIV Teknik Elektro Industri pada Jurusan Teknik Elektro Fakultas Teknik Universitas Negeri Padang.

Dr. Ta'ali, M.T, Lahir di Pekalongan, 16 Oktober 1963. Menyelesaikan studi S1 di IKIP padang tahun 1989, Pendidikan S2 di Institut Tekneologi Bandung tahun 1999. Pendidikan S3 di Universitas Negeri Yogyakarta tahun 2017. Staf pengajar pada jurusan teknik elektro FT UNP sejak tahun 1990 sampai sekarang. 